\title{
Actinomycetes Diversity among rRNA Gene Clones and Cellular Isolates from Sambhar Salt Lake, India
}

\author{
A. K. Yadav, ${ }^{1}$ S. Vardhan, ${ }^{1}$ S. Kashyap, ${ }^{1}$ M. Yandigeri, ${ }^{1,2}$ and D. K. Arora ${ }^{1,3}$ \\ ${ }^{1}$ National Bureau of Agriculturally Important Microorganisms, Kushmaur, Katholi, Maunath Bhanjan, Uttar Pradesh 275101, India \\ ${ }^{2}$ National Bureau of Agriculturally Important Insects, H.A. Farm Post, Bellary Road, Bangalore, Karnatka 560024, India \\ ${ }^{3}$ Sher-e-Kasmir University of Agriculture Science \& Technology of Jammu, Main Campus, Chatta, Jammu (J\&K) 180009, India
}

Correspondence should be addressed to S. Kashyap; sudhanshukshyp@gmail.com

Received 3 August 2013; Accepted 11 September 2013

Academic Editors: H. Takami and J. Yoon

Copyright (C) 2013 A. K. Yadav et al. This is an open access article distributed under the Creative Commons Attribution License, which permits unrestricted use, distribution, and reproduction in any medium, provided the original work is properly cited.

\begin{abstract}
The vertical stratification of actinomycetes diversity in Sambhar salt lake (India's largest salt lake) was investigated by using cultivable and uncultivable approaches. The isolates from cultured approaches were clustered on the basis of cultural, morphological, biochemical, and cell wall characteristics, and results were further strengthened by $16 \mathrm{~S}$ rDNA-RFLP into five major groups. 16S rDNA sequencing of the representative isolates from each clusters was identified as belonging to Streptomyces, Actinopolyspora, Microbispora, Saccharopolyspora, and Actinoplanes genera, while culture independent group was established as Streptomyces (130 clones, 20 OTUs), Micromonospora (96 clones, 7 OTUs), Streptosporangium (79 clones, 9 OTUs), Thermomonospora (46 clones, 8 OTUs), and Dactylosporangium (58 clones, 8 OTUs). The diversity assessment using Shannon and Wiener index was found to be 1.55 , $1.52,1.55$, and 1.49 from surface lake water, at depth of $1.5 \mathrm{~m}$, shallow layer of water with algal population, and finally at depth of $2.5 \mathrm{~m}$, respectively. We observed diversity in terms of the species richness as Streptomyces is dominant genus in both culture dependent and culture independent techniques followed by Microbispora (culture dependent methods) and Micromonospora (culture independent method) genera, respectively.
\end{abstract}

\section{Introduction}

Aquatic realms of biosphere cover $75 \%$ of the earth's surface and represent $95 \%$ of the biosphere which provides the largest inhabitable space for living organisms, particularly microbes $[1,2]$. The Sambhar salt lake has attracted attention over the past century due to its pronounced hypersalinity and being a key wintering area for northern shoveller and black-headed gull and other northern Asian migratory birds. Earlier, hypothesis for hypersalinity has suggested a wind born source of salt from Ran of Kutch [3], an inland Tethys sea during the Tertiary period [4], and dissolution of halite bed in lake area [5]. More recent isotopic studies have clearly refuted the marine origin and have suggested that the lake brine is yearly replenished by environmental precipitation and surface runoff mediated weathering $[6,7]$. In the last two decades, several attempts have been made for phylogenetic characterization of microflora from salt lake in different parts of the world [8]. Though soil actinomycete diversity has been extensively studied, relatively few efforts with aquatic actinomycetes have been attempted. Research on the biodiversity of aquatic actinomycetes is not only important for basic studies but also necessary for its exploitation. The cloning of rRNA genes (rDNAs) from natural ecosystems precipitated a fundamental shift in microbial ecology away from the study of cultured strains and towards molecular approaches that emphasized the importance of in situ diversity. The great plate count anomalies [9] led to the formulation of two nonexclusive hypotheses that could be applied generally to many ecosystems: firstly bacterial communities are composed of known species that are capable of forming colonies on agar plates but do so with low efficiency, and secondly it is composed of many unknown species that cannot easily be grown on common microbiological media [10]. There are only few reports from Sambhar salt lake, belonging to green alga Dunaliella salina and the bacterium Serratia sambhariana. Till date, there are no reports available on the actinomycetes diversity from Sambhar lake. The evaluation of actinomycetes 
population is required for understanding its biogeography, community assembly, and ecological processes [11] within a particular exotic niche. Exotic niches harbor population of microorganisms that are a source of several commercially important products like enzymes and antibiotics, one such extreme niche the Sambhar salt lake has maintained some degree of pristine quality and their biotechnological potential has remained unrealized. This is the first report to decipher the actinomycetes diversity from Sambhar lake. Recent studies using both cultural independent molecular approaches and culture-based methods demonstrated abundant novel actinobacterial assemblage in aquatic ecosystems; with this perception in this study, we combined both the culture dependent and culture independent methods for the diversity analysis which enables us to access diversity more precisely than does either method alone $[12,13]$. In the present work, we reported the results of a study in which HhaI/CfoI and TaqI restriction fragment length polymorphism (RFLP) patterns and partial gene sequences were used to compare the $16 \mathrm{~S}$ rDNAs subunit isolates to actinobacterial $16 \mathrm{~S} \mathrm{rDNAs}$ cloned, with the intention of screening these isolates for potentially useful enzymes and metabolites. Here we decipher the diversity of the actinomycetes in Sambhar salt lake.

\section{Material and Methods}

2.1. Site Description, Samples Collection, and Water Analysis. Sambhar is an elliptical shallow lake $\left(26.967^{\circ} \mathrm{N} \& 75.083^{\circ} \mathrm{E}\right)$, with a maximum length of $22.5 \mathrm{Km}$ and width of 3.2 to 11.2 $\mathrm{Km}$ with the total catchment area of about $225 \mathrm{Km}^{2}$ with an average depth of 1-3 m (Figure 1). The lake is bounded by Aravali hill with precipitation of $100-500 \mathrm{~mm}$ of South Western monsoon and an average annual temperature of $23^{\circ} \mathrm{C}$ to a maximum of $45^{\circ} \mathrm{C}$. Water samples $(0.8-1 \mathrm{~L})$ were collected in a sterile scotch bottles by submerging at surface, $1.5 \mathrm{~m}, 2.5 \mathrm{~m}$ depth of lake in random manner. Samples were brought into laboratory under refrigerated condition for further studies. Before analysis the samples were brought to room temperature and their chemical characteristics were determined using standard methods. The $\mathrm{pH}$ was measured by $\mathrm{pH}$ meter, chloride was determined by argentometric method, and sulphate was estimated gravimetrically after precipitation in $\mathrm{HCl}$ as barium sulphate [14]. Macronutrients $(\mathrm{Na}, \mathrm{K}, \mathrm{Ca}$, and $\mathrm{Mg}$ ) were determined using atomic absorption spectrophotometer (Brunswick 301).

2.2. Isolation and Characterization of Actinomycetes Isolates. Isolation of actinomycetes was done by enrichment method of Wang et al. [15]. Standard methods were used to study the morphological, physiological, and biochemical traits [1619]. Morphological characteristics of actinomycetes were observed on light microscopy (GX10) [16], as well as on scanning electron microscopy [20]. For chemotaxonomic characterization, cell wall preparations and whole cell analysis were done by the modified procedure of Becker et al. [21].

2.3. 16S rDNA and Clone Library. Genomic DNA of cellular isolates and environmental samples were extracted

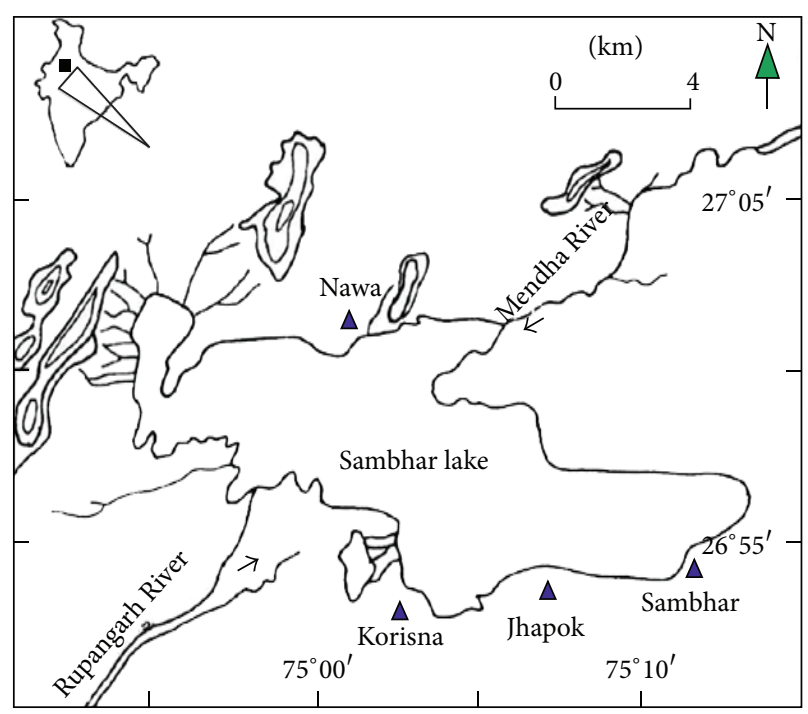

FIGURE 1: Schematic map of sampling site, Sambhar salt lake, India.

by the modified method of Boudjella et al. [22] and Fuhrman et al. [23]. PCR amplification of $16 \mathrm{~S}$ rDNA for cellular isolates was carried out by using universal primers fD1 ( $5^{\prime}$-GAGTTTGATCCTGGCTCA-3') and RP2 (5' -CGGCTACCTTGTTACGACTT-3') Weisburg et al. [24], while environmental sample DNA, genus specific $16 \mathrm{~S}$ rDNA primers (Streptomyces, Micromonospora, Dactylosporangium, Thermomonospora, and Streptosporangium genera), and amplification conditions were used according to Monciardini et al. [25]. Analysis of the 16S r RNA genes was conducted according to the method of Hobel et al. [26].

2.4. Restriction Fragment Lengths Polymorphism Analysis (RFLP) and Sequencing. PCR product from cellular isolates and plasmids from gene clones were restricted with a set of two restriction enzymes separately (HhaI/CfoI and TaqI) according to the manufacturer's instructions (Genei, India). The banding pattern development was analyzed by horizontal electrophoresis in 2.5\% agarose gels and documented on a gel documentation system (Alpha Imager, USA). PCR products were purified using purification kit (Genei, India). For the sequencing of cellular clones, $1 \mu \mathrm{g}$ of purified PCR product was sequenced using same primer set as used in PCR amplification, and for the gene clones, replicate PCR products were pooled, separated on agarose gel, and band was purified using Gel extraction kit (GeNei, India). Clones were constructed with the Invitrogen TOPO TA cloning kit and purified using GeNei purification kit (GeNei, India). Purified plasmids were digested with EcoRI to separate inserts and run on agarose to determine insert size. The PCR products and plasmid insert were sequenced with the Big Dye terminator Cycle Sequencing kit (Applied Biosystems model no. 3130XL). Clone sequences were checked by CHIMERACHECK program (http://rdp.cme.msu.edu/).

2.5. Phylogenetic Analysis. Scoring and data analysis of restriction profiles were done in a binary matrix, and the 
data was used for calculating Jaccard's similarity coefficient [27]. Dendrogram was constructed by neighbor-joining [28] unweighted pair group arithmetic mean (UPGMA) method [29]. In order to estimate the goodness of fit of cluster analysis, cophenetic value matrices were calculated and compared with the original similarity matrices that were UPGMA clustered and tree was constructed by NJ methods to classify unknown isolates into closely related standard isolates by using the NTSYSpc analysis package (Version 2.02e; Applied Biostatistics Inc., Setauket, New York, USA). Phylogenetic analysis was done according to what was previously described by Stach et al. [30]. Phylogenetic identity of actinomycetes was determined by RUDP-BLAST result, sequence was aligned by Clustal $\mathrm{X}$ and phylogeny calculations, and dendrogram was constructed by Mega 4.1 software package using maximum parsimony methods [31]. Bootstrap analysis was conducted using 1000 resampling of data.

2.6. Statistical Analysis. In order to compare the bacterial diversity within the samples, 16S rRNA gene sequences showing $>97 \%$ sequence similarity were grouped into the same OTU (phenotype). The species diversity within a community or habitat is measured by alpha $(\alpha)$ diversity which has two components: species richness and evenness, and is calculated into single index, that is, Shannon and Wiener index. It was calculated by using software Ecosim (version 5.0.1) (http://www.ecosim.ca/ELCWebApp/ecological_land_classification/ELC_eTool.html). Rarefaction analysis was done using the site Online Calculation (http://fastgroup.sdsu.edu/cal_tools.htm). The 16S rRNA gene clone libraries were compared using principal component analysis (PCA). PCA was performed to group or separate samples based on the biogeochemical parameters (total count, $\mathrm{pH}$ values, $\mathrm{SO}_{4}{ }^{2-}, \mathrm{Na}^{+}, \mathrm{K}^{+}, \mathrm{Ca}^{2+}$ and $\mathrm{Mg}^{2+}$ ) and the percentage of OTUs in each sample.

2.7. Nucleotide Sequence Accession Numbers. Gene bank nucleotide accession numbers for sequences and their respective identified names were mentioned in Supplementary table of the Supplementary Material available online at http://dx.doi.org/10.1155/2013/781301.

\section{Results and Discussion}

The aquatic regime for actinomycetes remains untouched for a long time in India [32], and species isolated from this biome are mostly novel with possible sources of extracellular enzymes and antibiotics [33]. Sambhar is the largest elliptical shaped salt lake which covers $3 / 4$ salt productions in India. The actinomycetes density was found to vary between $1-13 \times$ $10^{4} \mathrm{CFU} \mathrm{mL}^{-1}$ in the lake water samples. The cellular isolates were initially differentiated on the basis of microscopic (Figure 2), biochemical and chemotaxonomic parameters (Table 2). Further, based on 16S rDNA-RFLP fingerprinting all the isolates were clustered into five major groups, that is, I (7 isolates), II (17 isolates), III (6 isolates), IV (10 isolates), and V (6 isolates), and were identified primarily up to genera level as Actinopolyspora sp., Streptomyces sp.,
Actinoplanes sp., Microbispora sp., and Saccharopolyspora sp., respectively (Table 2 ). The representative isolates of each group were subjected to $16 \mathrm{~S}$ rDNA sequencing, and postalignment followed by phylogenetic analysis was carried out with closest representative in RDP database and were identified as Actinopolyspora salina (R29), Streptomyces hygroscopicus (R3), Actinoplanes regularis (R18), Saccharopolyspora taberi (R40), and Microbispora diastatica (R13), respectively (Figure 3(b)).

In uncultivable approaches, highest yield of DNA was recovered from surface water than other samples (surface water $>1.5 \mathrm{~m}>2.5 \mathrm{~m}$ ) respectively, followed by the amplification of 16S rDNA using specific primers of Streptomyces, Micromonospora, Streptosporangium, Thermomonospora, and Dactylosporangium of corresponding molecular weight of $0.6,1.0,0.5,0.8$, and $0.58 \mathrm{~kb}$, respectively. Phylogenetic analysis of representative isolates sequences was done by multiple alignment of representative isolates with its closest relative sequences from public RDP database. A total of 409 clones were obtained from total samples of Sambhar salt Lake Streptomyces (32\%) > Micromonosporaceae (24\%) $>$ Streptosporangiaceae $(19 \%)>$ Dactylosporangiaceae $(14 \%)$ $>$ Thermomonosporaceae (11\%) (Table 1). All the amplified PCR products of reference were further classified by RFLP analysis; the group representative clones were identified by sequencing. All clones were clustered together by Pattern Restriction Analysis fingerprint analysis; representative clones were sequenced and found to be a total of 55 OTUs by BLAST searches (Supplementary Table). One representative of each OTU was taken, and its sequence was aligned with its closest relatives. The analysis of the constructed phylogenetic tree (Figure 3(a)) revealed presence of clones branching among 5 actinobacterial divisions, including Streptomyces (130 clones, 20 OTUs), Micromonospora (96 clones, 7 OTUs), Streptosporangium (79 clones, 9OTUs), Thermomonospora (46 clones, 8OTUs), and Dactylosporangium (58 clones, 8 OTUs). Maximum number of clones was found from Surface lake water (133 clones) and minimum number from shallow water layer (77 clones). However, vertical profiling of actinomycetes population also showed that surface water had maximum number of clones (133), followed by lake water at the depth of $1.5 \mathrm{~m}$ (112) and at $2.5 \mathrm{~m}$ depth (87 clones) respectivelya and contained a majority of clones (OTUs) (Table 1). The Shannon and Wiener index in a Sambhar salt lake (on the basis of number of OTUs present in the different samples of lakes) was calculated to be $1.55,1.52,1.55$, and 1.49 from surface lake water, lake water at depth of $1.5 \mathrm{~m}$, shallow layer of water with algal population, and finally lake water at depth of $2.5 \mathrm{~m}$, respectively. In this study we focused on cultivable and uncultivable diversity of actinomycetes at genus and species level as a first step toward a practical application of diversity analysis of these microbes. By using the classical approaches, we are able to identify $70 \%$ isolates up to generic level; it reduces isolate number that is required in the application of the more costly DNA sequence analysis. Molecular diversity study showed a good variability with $16 \mathrm{~S}$ rDNA-RFLP of all the isolates with respect to their morphological and chemotaxonomic characteristics. 


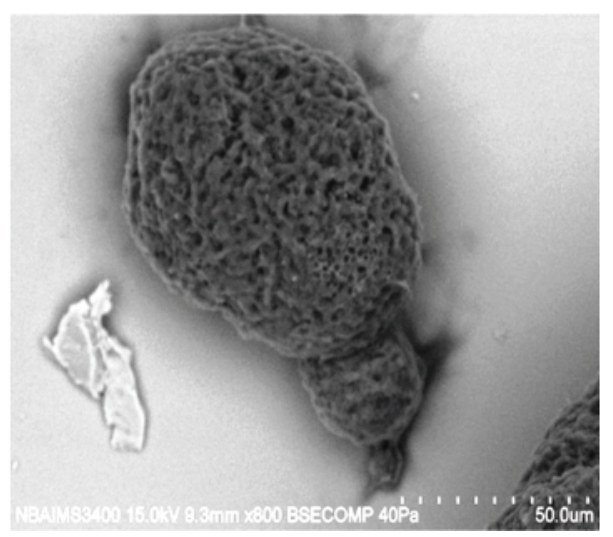

(a)

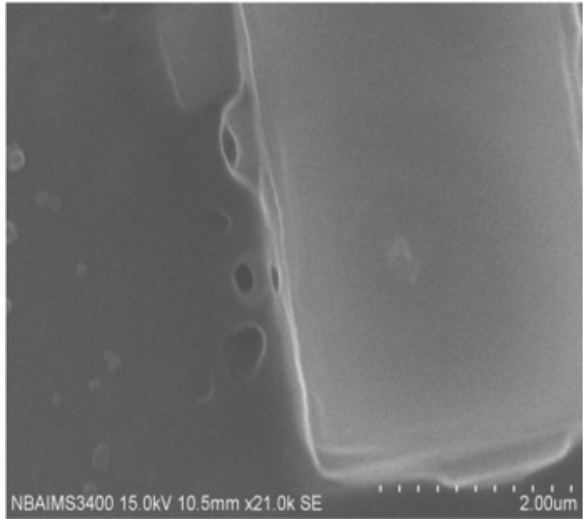

(b)

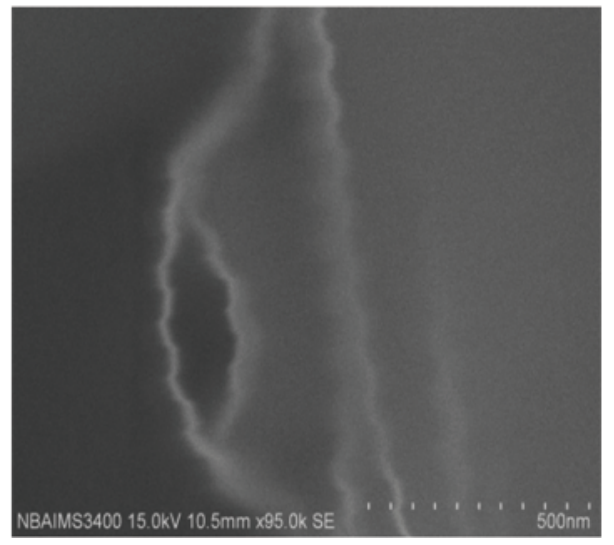

(c)

FIGURE 2: Scanning electron microscopy (SEM) of Streptomyces cellular isolate isolated from Sambhar salt lake, India, (a) showing globular sporangiophore, (b) sporangial pore, and (c) enlargement showing wavy sporangial pore architecture.

Restriction analysis has been used to study genotypic diversity analysis and differentiation of actinomycetes within genus and/or species levels [34-36]. Sambhar salt lake had good number of actinomycetes diversity, although culturable and unculturable diversity analysis techniques have their own advantages and disadvantages [37] by using polyphasic identification strategies for culture dependent actinomycetes, we identified 4 genera, of which Streptomyces (17 morphotypes) was a dominant genus followed by Microbispora (8), Actinopolyspora (7), Saccharopolyspora (6), and Actinoplanes (6), respectively, whereas for culture independent diversity, we found 52 species with 5 genera of actinomycetes, namely, Streptomyces followed by Micromonospora, Streptosporangium, Dactylosporangium, and Thermomonospora, respectively. Other studies also reported that Streptomyces is the dominant genus within actinobacterial population present from aquatic habitat [37] followed by Micromonospora [38]. Vijay et al. [39] reported 9 genera (Streptomyces as dominant genus) from 18 marine sediment samples (halophilic nature) from Bay of Bengal, India. The difference in diversity between various depths of extreme environments is clearly observed in Sambhar salt lake. Our result showed that surface water has total 133 clones with 47 OTUs followed by lake water at depth of $1.5 \mathrm{~m}$ (112 clones with 39 OTUs), lake water at depth of $2.5 \mathrm{~m}$ (87 clones with 39 OTUs). Field et al. [40] also reported that the bacterial community with respect to species composition in aquatic system decreases vertically from surface water.

The main cause of fluctuation of diversity may be attributed to nutrient scarcity and oxygen requirement at sediment than surface water [41]. Till date very less information regarding microbial diversity functions, such as nutrient cycling, degradation of xenobiotics, and ecosystem stability, is known. Application of diversity estimators coupled with diversity indices and community dominance enables the discrimination of environments, either geographically isolated or a particular specific niche. Extreme ecosystems that are characterized by high dominance of particular organisms require a smaller sampling size to determine the main elements of their community structure. Diversity indices were used to determine species richness and evenness into single index, that is, Shannon index, which indicates pattern of diversity, shifting of diversity, and so forth [42]. Our calculations also indicate that Shannon index decreases from surface water (1.55) to lake water at depth of $1.5 \mathrm{~m}(1.52$,$) and$ finally $2.5 \mathrm{~m}$ (1.49) at various depths of Sambhar lake, respectively. The implementation of above described techniques will enhance bioprospecting strategies in several respects like 


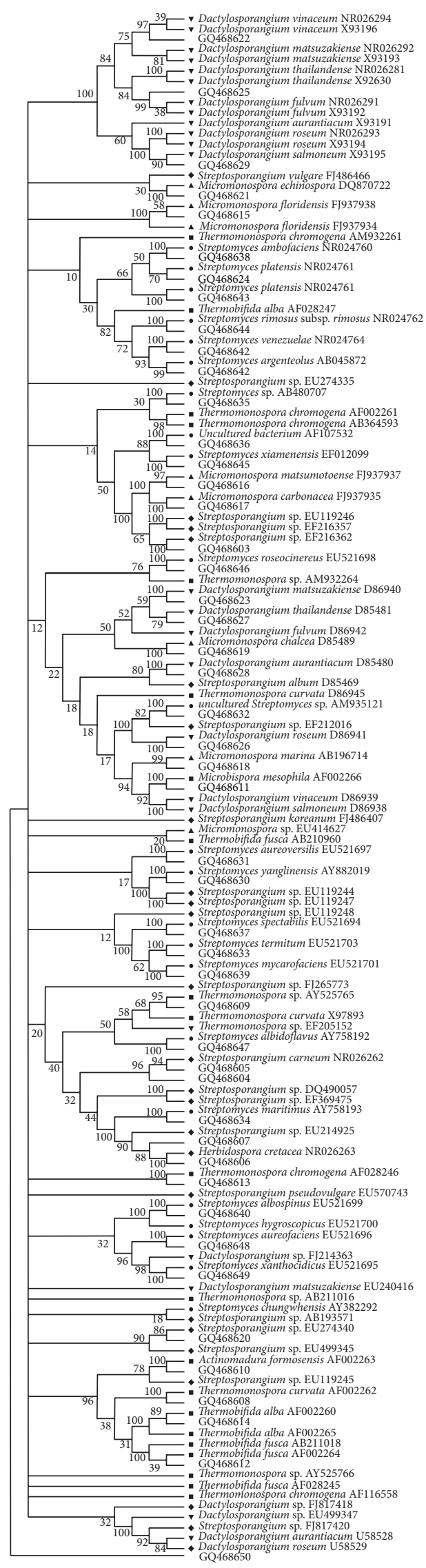

(a)

Figure 3: Continued. 


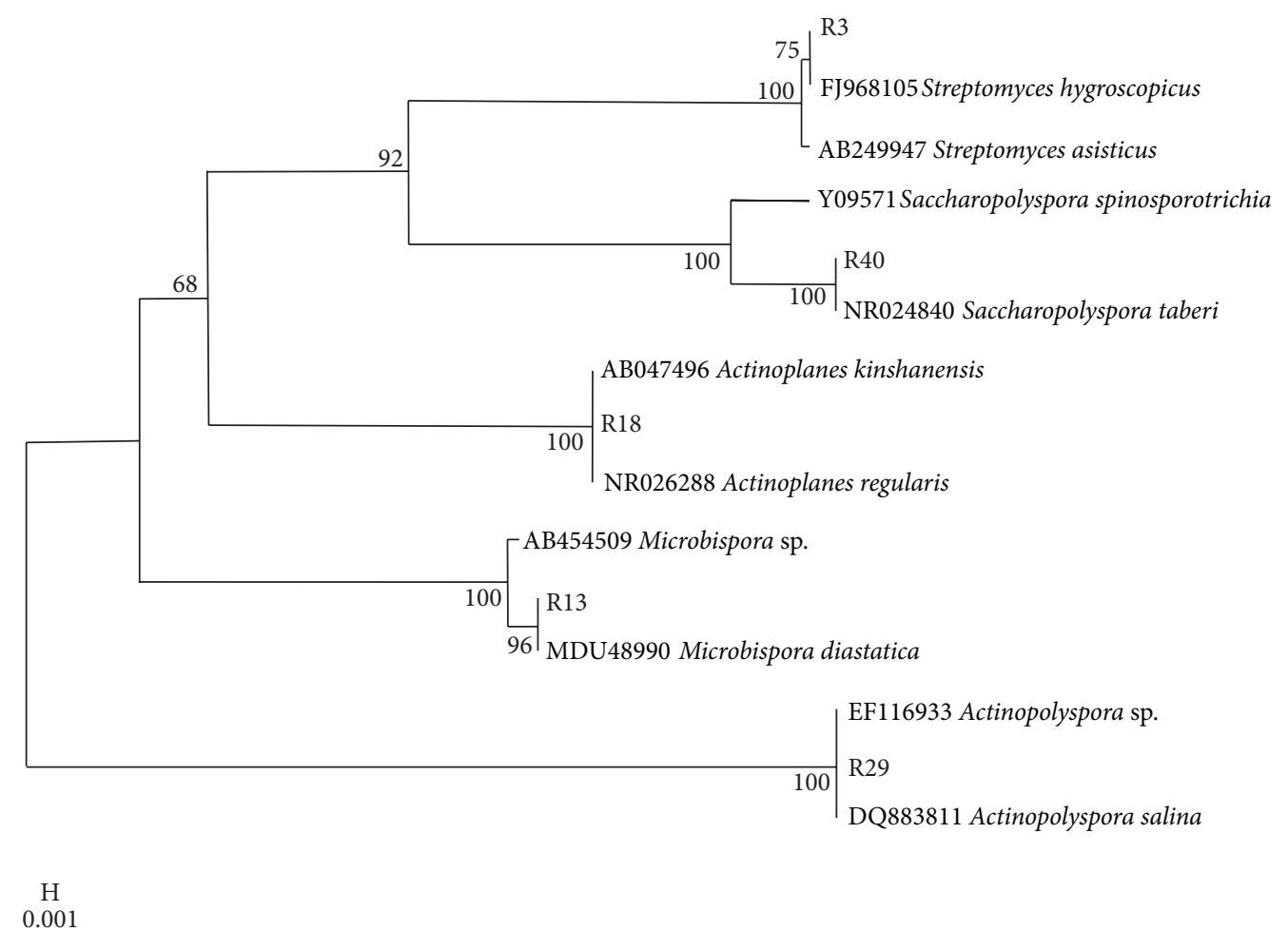

(b)

Figure 3: (a) Phylogenetic relationships among species of the genera Streptomyces (600 bp); Micromonospora (1 kb); Streptosporangium (500 bp); Thermomonospora ( $800 \mathrm{bp}$ ), and Dactylosporangium (580 bp) based on partial nucleotide sequences of the 16S rDNA. The tree was constructed using the maximum parsimony method. Percentages at nodes represent levels of bootstrap support from 1000 resampled datasets. GenBank accession numbers are given in parentheses and (b). Phylogenetic analysis of actinomycetes isolates from Sambhar salt lake based on partial nucleotide sequences $(1.5 \mathrm{~kb})$ of the $16 \mathrm{~S} \mathrm{rDNA}$. The tree was constructed using the neighbor-joining method. Percentages at nodes represent levels of bootstrap support from 1000 resampled datasets. Bootstrap values less than $50 \%$ are not shown. The bar indicates $0.001 \%$ estimated sequence divergence

presence or absence of species in the environment being sampled; this information can be employed in the design of cultivation strategies.

Molecular characterization of all the isolates was carried out by restriction analysis of $16 \mathrm{~S}$ rDNA with HhaI/CfoI and TaqI restriction enzymes, respectively, and representative isolates were sequenced, while in the case of culture independent study, we used five specific primers for different Actinomycetales family followed by restriction analysis of amplified 16S rDNA products with same enzymes mentioned above and representative isolates were cloned, sequenced, and identified as Streptomyces as dominant genera in Sambhar salt lake by using both culture dependent and culture independent methods followed by Microbispora (culture dependent) and Micromonospora (culture independent techniques), respectively. Here we obtained evidence for presence of high species diversity of Actinomycetes in the Sambhar salt lake of India. The restriction enzymes used in present study specifically recognize the sequence "GCG/C" and "T/CGA." The results of the different RFLP patterns obtained allowed us to effectively differentiate the strains into distinct groups of actinobacteria. This rapid and convenient method can be very useful in grouping actinobacterial isolates efficiently, although experimental caution must be taken during the phylogenetic analysis, while using the RFLP approach [43].

The result of PCA based on lake water properties are shown in Figure 4 and the principal component factor 1 and 2 explained $100 \%$ of the total variances. The PCA plot indicates that Micromonosporaceae, Streptomycetaceae, and Dactylosporaceae are closely grouped while their distribution was influenced by alkalinity and sulphate concentration while Thermonosporaceae and Streptosporangaeae are grouped separately and their distribution is influenced by $\mathrm{pH}$, potassium, sodium, and calcium ions concentration. Since biogeochemical properties may be influence by the heterogeneity observed in the samples with respect to specific OTUs. The Zhang et al. [44] demonstrated that microbial diversity was not related to $\mathrm{Ca}^{2+}$ concentration but features like $\mathrm{pH}$ influence the microbial community composition and diversity [45]. Thus it may be implicated that closely associated parameters and a key parameters that influence observed differences in the percentage of specific OTUs in the 16S rRNA gene libraries. Information about the composition of the microbial community is of key importance for better understanding of various processes in the aquatic ecosystem [46-48]. Molecular methods based on 16S rRNA are now widely 
TABLE 1: Cultural, biochemical, and chemotaxonomic characterization of cellular isolates.

\begin{tabular}{|c|c|c|c|c|c|}
\hline \multirow{2}{*}{ Parameters } & \multicolumn{5}{|c|}{ Actinomycetes strains used } \\
\hline & R3 & R29 & $\mathrm{R} 13$ & $\mathrm{R} 40$ & $\mathrm{R} 18$ \\
\hline & \multicolumn{5}{|c|}{ Cell morphology (oat meal agar) } \\
\hline Aerial mycelia colour & White & Grey & Yellow & White & Ash \\
\hline Substrate mycelia colour & Yellow & Brown & Colorless & Yellow & Light brown \\
\hline \multirow[t]{2}{*}{ Soluble pigment } & - & Brown & - & Yellow & - \\
\hline & \multicolumn{5}{|c|}{ Growth pattern } \\
\hline Optimum temperature & $25-28$ & $25-37$ & $25-28$ & $30-37$ & $30-45$ \\
\hline \multirow[t]{2}{*}{ Optimum pH } & $7.0-8.0$ & $7.0-7.5$ & $6.5-7.5$ & $7.0-8.0$ & $7.0-7.8$ \\
\hline & \multicolumn{5}{|c|}{ Degradation pattern } \\
\hline Tween 80 & + & + & + & + & - \\
\hline Starch hydrolysis & + & + & - & + & + \\
\hline Casein hydrolysis & + & + & + & + & + \\
\hline Tyrosine degradation & + & + & + & + & - \\
\hline Xanthine degradation & + & + & - & - & - \\
\hline Xylan & - & + & + & + & + \\
\hline \multirow[t]{2}{*}{ Urea } & - & - & - & + & - \\
\hline & \multicolumn{5}{|c|}{ Carbon utilization pattern } \\
\hline $\mathrm{L}$-arabinose & - & + & - & + & + \\
\hline D-Fructose & + & + & - & + & + \\
\hline D-Galactose & + & + & - & + & + \\
\hline Glucose & + & + & + & + & + \\
\hline Sucrose & + & + & - & + & + \\
\hline Starch & + & + & + & + & + \\
\hline D-Xylose & - & + & + & + & + \\
\hline Rhamnose & - & + & + & - & - \\
\hline Raffinose & - & + & + & - & - \\
\hline Sodium acetate & + & + & + & - & + \\
\hline Sodium citrate & + & - & - & - & - \\
\hline \multirow[t]{2}{*}{ Sodium tartrate } & + & - & - & + & + \\
\hline & \multicolumn{5}{|c|}{ Chemotaxonomy } \\
\hline Cell wall type & IV & I & II & III & IV \\
\hline Diaminopimelic acid & Meso & LL & Meso & Meso & Meso \\
\hline Whole cell sugar & Arabinose, Galactose & Not characterized & Arabinose, Xylose & Glucose, Mannose, Ribose & Arabinose, Galactose \\
\hline
\end{tabular}

used to gain insight into microbial communities [45, 49]. While environmental factors and the microbial community structure in various lakes have been well documented [47], the two aspects were often considered independently.

The characterization of microbial community in different areas of a lake, mapped to differences in environmental parameters, may therefore provide information helpful in understanding the often complex processes. In recent years multivariate techniques such as principal component analysis (PCA) and others have been adopted to demonstrate the relationship between microbial community composition and environmental factors and have been proven to be more sensitive than univariate methods [50]. Using these techniques, the spatial and temporal variability in microbial community structure along with physiochemical factors, in lakes have been well documented, and several environmental parameters, such as nitrogen, $\mathrm{pH}$, and so forth, have been considered to be the key factors driving the changes in community comparison $[51,52]$. The rarefaction curves indicate that the actinobacterial population in the samples has a diversity coverage plateaued at 98.45 (Figure 5). The rarefaction curve analysis implied that these are likely to be minimum estimates of diversity parameters, such as Shannon index, Simpson's index, Coverage and evenness. Rarefaction curves having $98 \%$ confidence interval were constructed by comparing the number of clones in each $16 \mathrm{~S}$ rRNA gene library. The coverage (C) of each $16 \mathrm{~S}$ rRNA gene library, a measure of capture of diversity was calculated according to the equation $c=1-(n / N)$ where $\mathrm{n}$ is the number of different OTU types from a clone library that were encountered only once and $\mathrm{N}$ is the total number of sequences of clones in the library [53]. Several statistical approaches can be used 


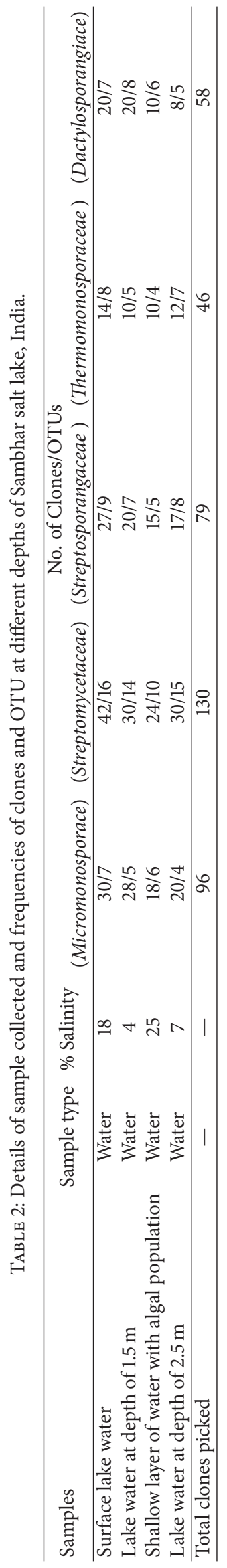




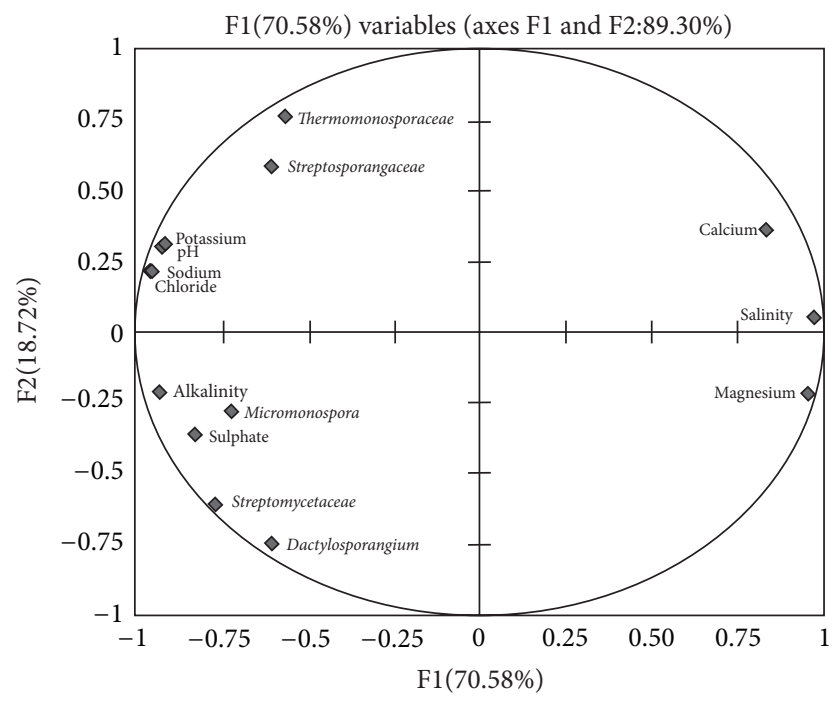

FIGURE 4: Rarefaction analysis showing sampling evenness. The inset graph shows reference ribotype plot.

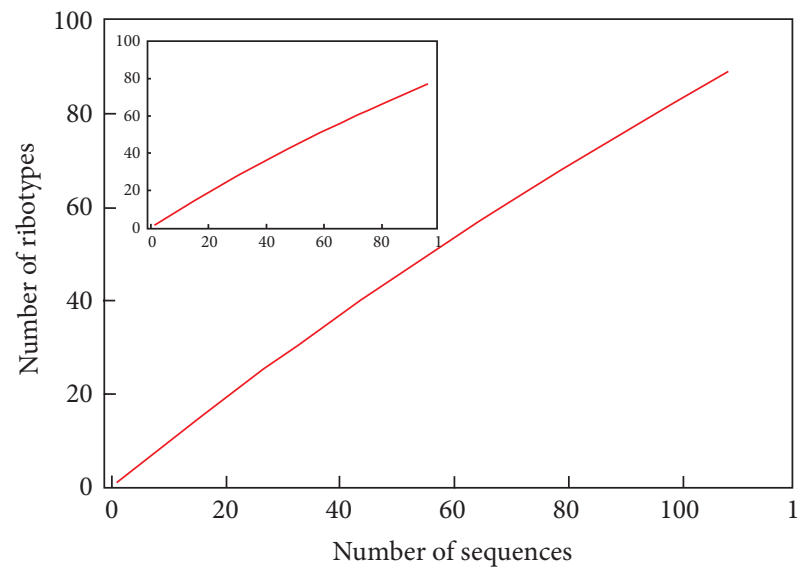

Figure 5: PCA analysis between the OTUs and biogeochemical parameters of Sambhar salt lake.

to analyze bacterial diversity estimates from the number of species found in relatively small samples [54]. Clone diversity was evaluated using Simpsons and Shannon-Wiener diversity indices. Both indices indicated a high diversity level of the microbial communities represented by the 16sRNA and cellular clones libraries. The Shannon-Wiener index is determined by OTU richness, whereas the Simpson index is highly influenced by the abundance of the most common OTU found in the sample [55] regarding the species richness. On the basis of the results of our investigation, we concluded that the actinomycetes diversity in the Sambhar salt lake is high at both genus and species level. So far, only a few reports were available of systematic investigation of actinomycetes diversity from salt lake of India, and these reports provide little or no information about the actinomycetes diversity at genus and species level.

\section{Conclusion}

We examined 46 morphologically different actinomycetes isolates using the culture dependent isolates. They were grouped into five clusters on the basis of morphological, biochemical, and chemotaxonomic characteristics. Molecular characterization of all the isolates was carried out by restriction analysis of $16 \mathrm{~S} \mathrm{rDNA}$ with $\mathrm{HhaI} / \mathrm{CfaI}$ and TaqI restriction enzymes, respectively, and representative isolates were sequenced, while in the case of culture independent study, we used five specific primers for different Actinomycetales family followed by restriction analysis of amplified $16 \mathrm{~S}$ rDNA products with same enzymes mentioned above, and representative isolates were cloned, sequenced, and identified as Streptomyces as dominant genera in Sambhar salt lake by using both culture dependent and culture independent methods followed by Microbispora (culture dependent) and Micromonospora (culture independent techniques), respectively. Here we obtained evidence for high species diversity of actinomycetes in the Sambhar salt lake of India.

\section{Conflict of Interests}

The authors declare that obviously there is no conflict of interests regarding the publication of this paper.

\section{Acknowledgment}

The study was supported by the Application of Microbes in Agriculture and Allied Sectors (AMAAS) Network Project grant from Indian Council of Agricultural Research (ICAR) New Delhi, India.

\section{References}

[1] S. Das, P. S. Lyla, and S. A. Khan, "Marine microbial diversity and ecology: importance and future perspectives," Current Science, vol. 90, no. 10, pp. 1325-1335, 2006.

[2] V. S. Bernan, M. Greenstein, and W. M. Maiese, "Marine microorganisms as a source of new natural products," Advances in Applied Microbiology, vol. 43, pp. 57-90, 1997.

[3] T. H. Holland and W. A. K. Christie, "The origin of the salt deposits of Rajputana," Records of the Geological Survey of India, vol. 38, pp. 154-186, 1909.

[4] N. N. Godbole, “The salinity of Sambhar Lake," Bulletin of National Institute of Sciences, vol. 1, pp. 89-93, 1952.

[5] B. N. Bhattacharya, S. K. Gupta, B. P. Rishi, A. K. Mitra, and V. K. Kashyap, "Seasonal variation in the composition of Sambhar lake brine and possible origin of its salinity," Miscellaneous Publication of the Geological Survey of India, vol. 49, pp. 80-89, 1982.

[6] R. Ramesh, R. A. Jani, and R. Bhushan, "Stable isotopic evidence for the origin of salt lakes in the Thar Desert," Journal of Arid Environments, vol. 25, no. 1, pp. 117-123, 1993.

[7] D. N. Yadav, "Oxygen isotope study of evaporating brines in Sambhar Lake, Rajasthan (India)," Chemical Geology, vol. 138, no. 1-2, pp. 109-118, 1997.

[8] H. Urakawa, T. Yoshida, M. Nishimura, and K. Ohwada, "Characterization of depth-related population variation in microbial 
communities of a coastal marine sediment using 16S rDNAbased approaches and quinone profiling," Environmental Microbiology, vol. 2, no. 5, pp. 542-554, 2000.

[9] J. T. Staley and A. Konopka, "Measurement of in situ activities of nonphotosynthetic microorganisms in aquatic and terrestrial habitats," Annual Review of Microbiology, vol. 39, pp. 321-346, 1985.

[10] S. J. Giovannoni, T. D. Mullins, and K. G. Field, "Microbial diversity in oceanic system, rRNA approaches to the study of unculturable microbes," in Molecular Ecology of Aquatic Microbes, I. Joint, Ed., pp. 217-248, Springer, Berlin, Germany, 1995.

[11] T. P. Curtis, W. T. Sloan, and J. W. Scannell, "Estimating prokaryotic diversity and its limits," Proceedings of the National Academy of Sciences of the United States of America, vol. 99, pp. 786-790, 2002.

[12] C. F. V. Hobel, V. T. Marteinsson, S. Hauksdóttir et al., "Use of low nutrient enrichments to access novel amylase genes in silent diversity of thermophiles," World Journal of Microbiology and Biotechnology, vol. 20, no. 8, pp. 801-809, 2004.

[13] C. M. Santegoeds, S. C. Nold, and D. M. Ward, "Denaturing gradient gel electrophoresis used to monitor the enrichment culture of aerobic chemoorganotrophic bacteria from a hot spring cyanobacterial mat," Applied and Environmental Microbiology, vol. 62, no. 11, pp. 3922-3928, 1996.

[14] M. C. Rand, A. E. Greenberg, M. J. Taras, and M. A. Franson, Standard Methods, American Public Health Association, 14th edition, 1975.

[15] Y. Wang, Z. S. Zhang, J. S. Ruan, Y. M. Wang, and S. M. Ali, "Investigation of actinomycete diversity in the tropical rainforests of Singapore," Journal of Industrial Microbiology and Biotechnology, vol. 23, no. 3, pp. 178-187, 1999.

[16] E. B. Shirling and D. Gottlieb, "Methods for characterization of Streptomyces species," International Journal of Systematic Bacteriology, vol. 16, pp. 169-189, 1966.

[17] J. G. Holt, N. R. Krieg, P. H. A. Sneath, J. T. Staley, and S. T. Williams, Bergey's Manual of Determinative Bacteriology, Williams and Wilkins, Baltimore, Md, USA, 9th edition, 1994.

[18] H. Nonomura, "Isolation, taxonomy and ecology of soil actinomycetes," Actinamycetalag'ica, vol. 3, pp. 45-54, 1988.

[19] S. T. Williams, M. E. Sharpe, and J. G. Holt, Berge's Manual of Determinative Bacteriology, vol. 4, Williams and Wilkins, Baltimore, Md, USA, 1989.

[20] A. K. Yadav, A. K. Srivastava, M. S. Yandigeri, S. K. Kashyap, D. R. Modi, and D. K. Arora, "Characterization of indigenous copper-resistant Streptomycetes from chickpea (Cicer arietinum L.) fields," Annals of Microbiology, vol. 60, no. 4, pp. 605-614, 2010.

[21] B. Becker, M. P. Lechevalier, and H. A. Lechevalier, "Chemical composition of cell-wall preparations from strains of various," Applied Microbiology, vol. 13, pp. 236-243, 1965.

[22] H. Boudjella, K. Bouti, A. Zitouni, F. Mathieu, A. Lebrihi, and N. Sabaou, "Taxonomy and chemical characterization of antibiotics of Streptosporangium Sg 10 isolated from a Saharan soil," Microbiological Research, vol. 161, no. 4, pp. 288-298, 2006.

[23] J. A. Fuhrman, D. E. Comeau, A. Hagstrom, and A. M. Chan, "Extraction from natural plankatonic microorganisms of DNA suitable for molecular biological studies," Applied and Environmental Microbiology, vol. 54, pp. 1426-1429, 1988.

[24] W. G. Weisburg, S. M. Barns, D. A. Pelletier, and D. J. Lane, "16S ribosomal DNA amplification for phylogenetic study," Journal of Bacteriology, vol. 173, no. 2, pp. 697-703, 1991.
[25] P. Monciardini, M. Sosio, L. Cavaletti, C. Chiocchini, and S. Donadio, "New PCR primers for the selective amplification of 16S rDNA from different groups of actinomycetesl," FEMS Microbiology Ecology, vol. 42, no. 3, pp. 419-429, 2002.

[26] C. F. V. Hobel, V. T. Marteinsson, G. Ó. Hreggvidsson, and J. K. Kristjánsson, "Investigation of the microbial ecology of intertidal hot springs by using diversity analysis of 16S rRNA and chitinase genes," Applied and Environmental Microbiology, vol. 71, no. 5, pp. 2771-2776, 2005.

[27] P. H. Sneath, "The application of computers to taxonomy," Journal of General Microbiology, vol. 17, no. 1, pp. 201-226, 1957.

[28] N. Saitou and M. Nei, "The neighbor-joining method: a new method for reconstructing phylogenetic trees," Molecular Biology and Evolution, vol. 4, no. 4, pp. 406-425, 1987.

[29] P. H. A. Sneath and E. R. Sokal, Numerical Taxonomy. The Principle and Practice of Numerical Classification, WH freeman, San Francisco, Calif, USA, 1973.

[30] J. E. M. Stach, L. A. Maldonado, D. G. Masson, A. C. Ward, M. Goodfellow, and A. T. Bull, "Statistical approaches for estimating actinobacterial diversity in marine sediments," Applied and Environmental Microbiology, vol. 69, no. 10, pp. 6189-6200, 2003.

[31] T. H. Jukes and C. R. Cantor, "Evolution of protein molecules," in Mammalian Protein Metabolism, H. N. Munro, Ed., pp. 21132, Academic Press, New York, NY, USA, 1969.

[32] S. Kerkar, Studies on bacteria of the dissimilatory reductive processes of the sulphur cycle from the salt pans of Goa [Ph.D. thesis], Departement of Marine Sciences; Goa University, 2004.

[33] J. A. Colquhoun, J. Mexson, M. Goodfellow, A. C. Ward, K. Horikoshi, and A. T. Bull, "Novel rhodococci and other mycolate actinomycetes from the deep sea," Antonie van Leeuwenhoek, vol. 74, no. 1-3, pp. 27-40, 1998.

[34] I. Harvey, Y. Cormier, C. Beaulieu, V. N. Akimov, A. Mériaux, and C. Duchaine, "Random amplified ribosomal DNA restriction analysis for rapid identification of thermophilic actinomycete-like bacteria involved in hypersensitivity pneumonitis," Systematic and Applied Microbiology, vol. 24, no. 2, pp. 277-284, 2001.

[35] A. Alves, O. Santos, I. Henriques, and A. Correia, "Evaluation of methods for molecular typing and identification of members of the genus Brevibacterium and other related species," FEMS Microbiology Letters, vol. 213, no. 2, pp. 205-211, 2002.

[36] F. J. Laurent, F. Provost, and P. Boiron, "Rapid identification of clinically relevant Nocardia species to genus level by $16 \mathrm{~S}$ rRNA gene PCR," Journal of Clinical Microbiology, vol. 37, no. 1, pp. 99-102, 1999.

[37] M. J. Ferris and D. M. Ward, "Seasonal distributions of dominant $16 \mathrm{~S}$ rRNA-defined populations in a hot spring microbial mat examined by denaturing gradient gel electrophoresis," Applied and Environmental Microbiology, vol. 63, no. 4, pp. 1375-1381, 1997.

[38] P. Laksmanaperumalsamy, D. Chandramohan, and R. Natarajan, "Antibacterial and antifungal activity of Streptomycetes from Porto Novo coastal environment," Marine Biology, vol. 11, pp. 15-24, 1978.

[39] M. Hayakawa and H. Nonomura, Selective Methods for Soil Actinomycetes (Japanese), Japan Association of Actinomycetes, 1993.

[40] R. K. Vijay, C. Muthukumar, N. Thajuddin, A. Panneerselvam, and R. Saravanamuthu, "Studies on the diversity of actinomycetes in the palk strait region of Bay of Bengal, India," Actinomycetol, vol. 21, pp. 59-65, 2007. 
[41] K. G. Field, D. Gordon, T. Wright et al., "Diversity and depthspecific distribution of SAR11 cluster rRNA genes from marine planktonic bacteria," Applied and Environmental Microbiology, vol. 63, no. 1, pp. 63-70, 1997.

[42] F. Wenzhofer, O. Holbu, and O. Kohls, "Deep penetrating bethnic oxygen profiles measured in situ by oxygen optodes," Deep Sea Research Part I, vol. 48, pp. 1741-1755, 2001.

[43] H. G. Washington, "Diversity, biotic and similarity indices. A review with special relevance to aquatic ecosystems," Water Research, vol. 18, no. 6, pp. 653-694, 1984.

[44] H. Zhang, Y. K. Lee, W. Zhang, and H. K. Lee, "Culturable actinobacteria from the marine sponge Hymeniacidon perleve: isolation and phylogenetic diversity by $16 \mathrm{~S}$ rRNA gene-RFLP analysis," Antonie van Leeuwenhoek, vol. 90, no. 2, pp. 159-169, 2006.

[45] J. Zeng, L. Yang, J. Li et al., "Vertical distribution of bacterial community structure in the sediments of two eutrophic lakes revealed by denaturing gradient gel electrophoresis (DGGE) and multivariate analysis techniques," World Journal of Microbiology and Biotechnology, vol. 25, no. 2, pp. 225-233, 2009.

[46] B. Nixdorf and J. Jander, "Bacterial activities in shallow lakesa comparison between extremely acidic and alkaline eutrophic hard water lakes," Hydrobiologia, vol. 506-509, pp. 697-705, 2003.

[47] Y. Koizumi, H. Kojima, K. Oguri, H. Kitazato, and M. Fukui, "Vertical and temporal shifts in microbial communities in the water column and sediment of saline meromictic Lake Kaiike (Japan), as determined by a $16 \mathrm{~S}$ rDNA-based analysis, and related to physicochemical gradients," Environmental Microbiology, vol. 6, no. 6, pp. 622-637, 2004.

[48] X. Zhao, L. Yang, Z. Yu et al., "Characterization of depth-related microbial communities in lake sediment by denaturing gradient gel electrophoresis of amplified 16S rRNA fragments," Journal of Environmental Sciences, vol. 20, no. 2, pp. 224-230, 2008.

[49] G. Muyzer, E. C. De Waal, and A. G. Uitterlinden, "Profiling of complex microbial populations by denaturing gradient gel electrophoresis analysis of polymerase chain reaction-amplified genes coding for 16S rRNA," Applied and Environmental Microbiology, vol. 59, no. 3, pp. 695-700, 1993.

[50] K. Haukka, E. Kolmonen, R. Hyder et al., "Effect of nutrient loading on bacterioplankton community composition in lake mesocosms," Microbial Ecology, vol. 51, no. 2, pp. 137-146, 2006.

[51] K. Haukka, E. Heikkinen, T. Kairesalo, H. Karjalainen, and K. Sivonen, "Effect of humic material on the bacterioplankton community composition in boreal lakes and mesocosms," Environmental Microbiology, vol. 7, no. 5, pp. 620-630, 2005.

[52] E. S. Lindström and A.-K. Bergström, "Community composition of bacterioplankton and cell transport in lakes in two different drainage areas," Aquatic Sciences, vol. 67, no. 2, pp. $210-$ 219, 2005.

[53] I. J. Good, "The population frequencies of species and the estimation of population parameters," Biometrika, vol. 40, pp. 237-264, 1953.

[54] J. B. Hughes, J. J. Hellmann, T. H. Ricketts, and B. J. M. Bohannan, "Counting the uncountable: statistical approaches to estimating microbial diversity," Applied and Environmental Microbiology, vol. 67, no. 10, pp. 4399-4406, 2001.

[55] J. B. Hughes and B. J. M. Bohannan, "Application of ecological diversity statistics in microbial ecology," in Molecular Microbial Ecology Manual, G. A. Kowalchuk, F. J. de Bruijn, I. M. Head, A. D. Akkermans, and J. D. van Elsas, Eds., pp. 1321-1344, Kluwer Academic, London, UK, 2nd edition, 2004. 

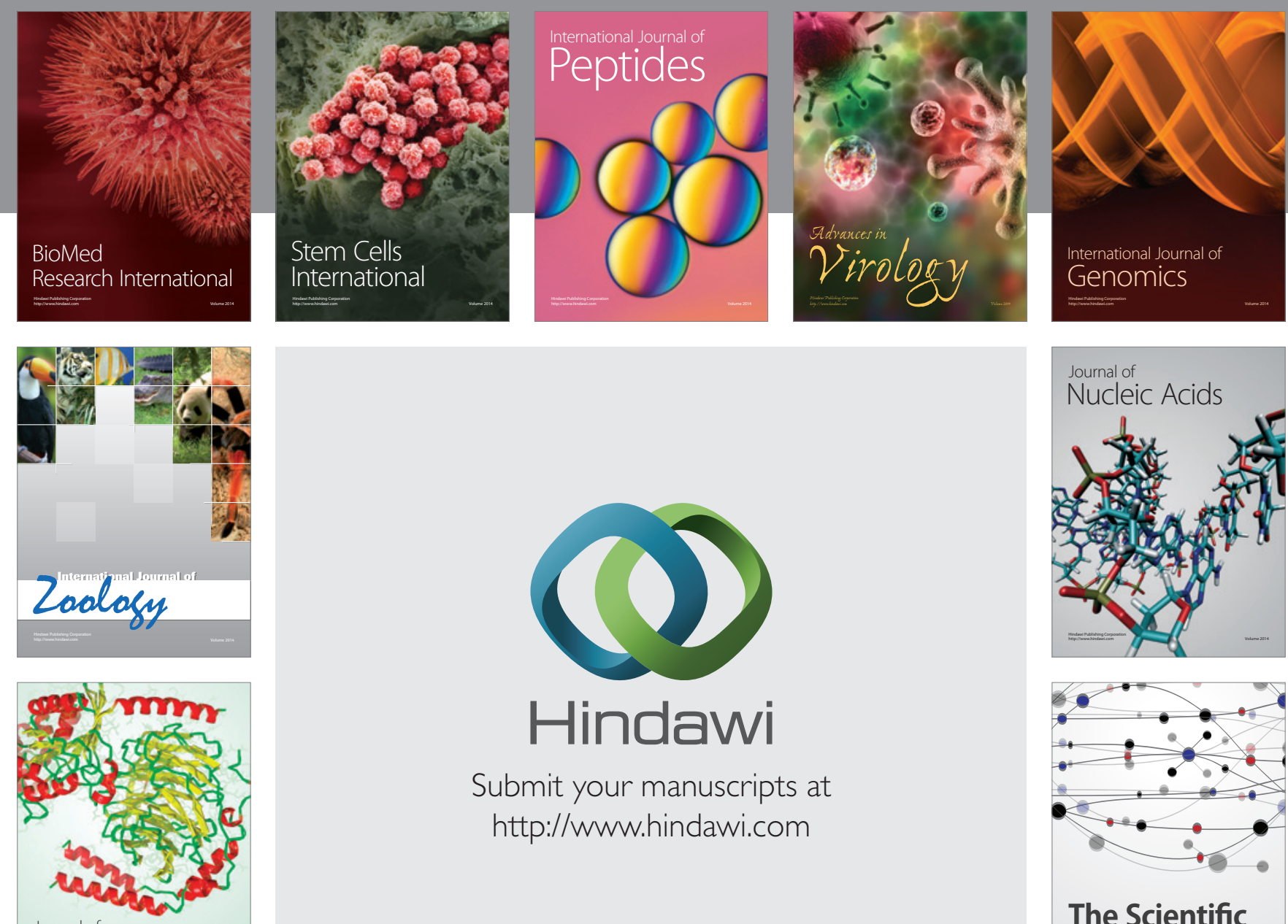

Submit your manuscripts at

http://www.hindawi.com

Journal of
Signal Transduction
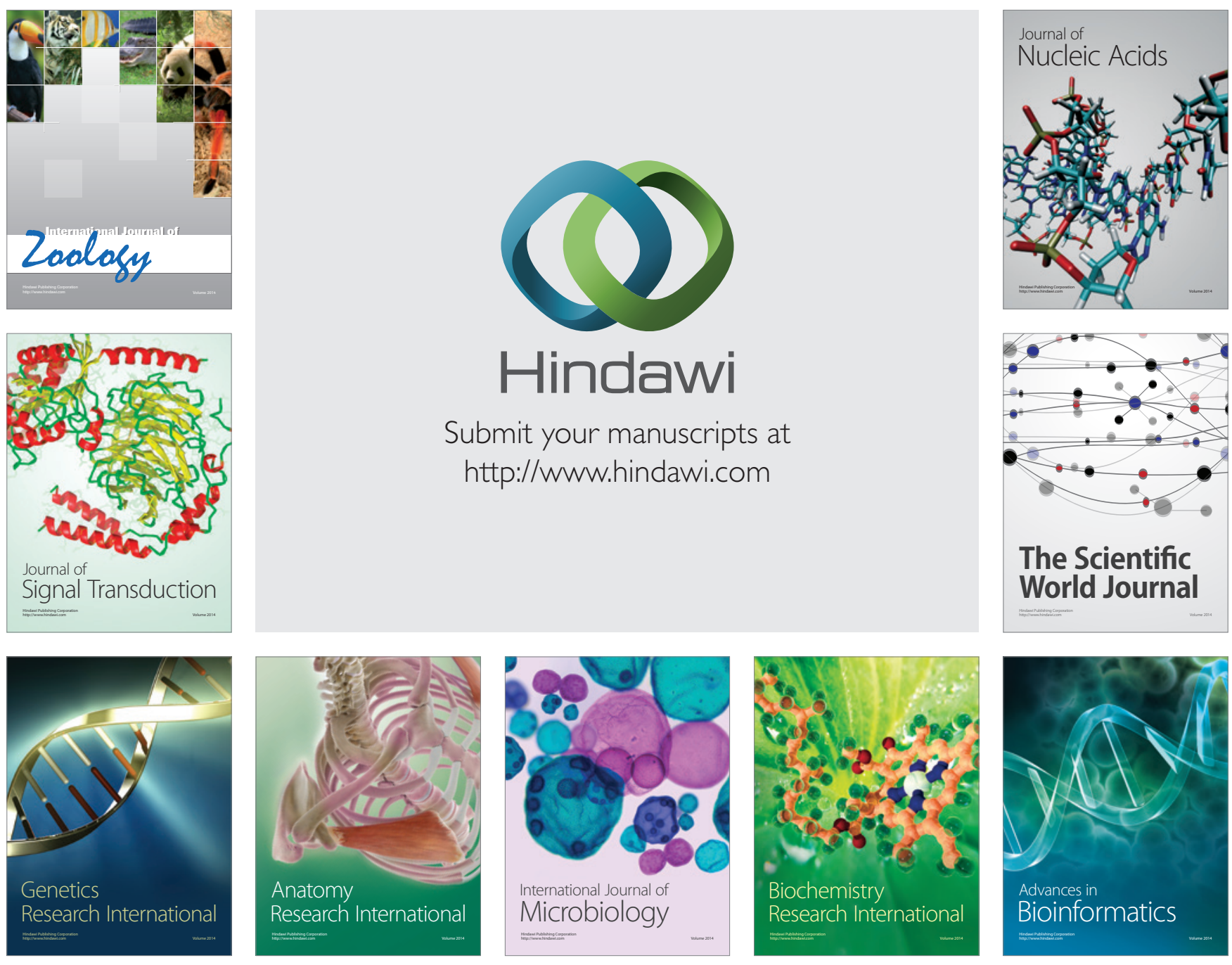

The Scientific World Journal
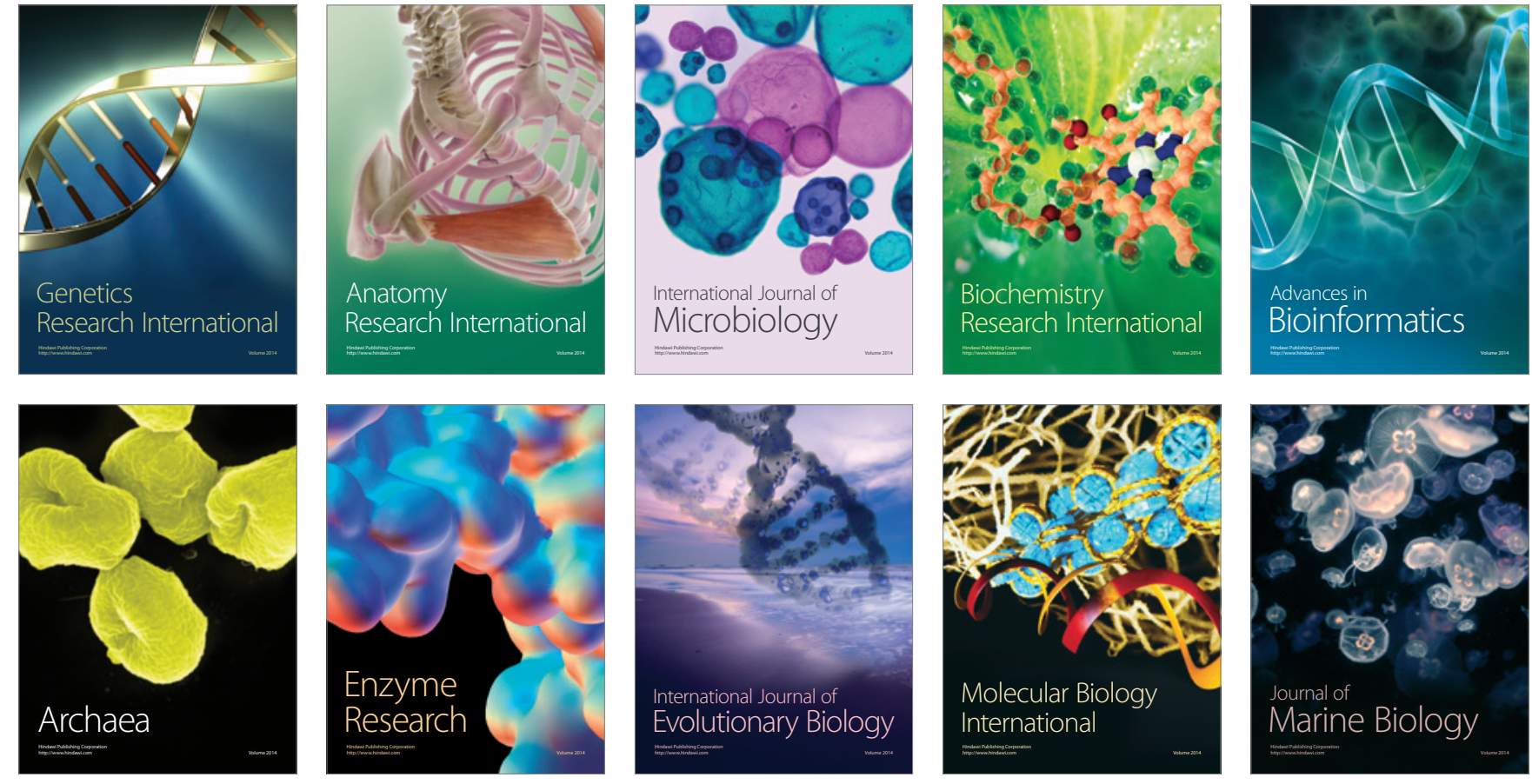